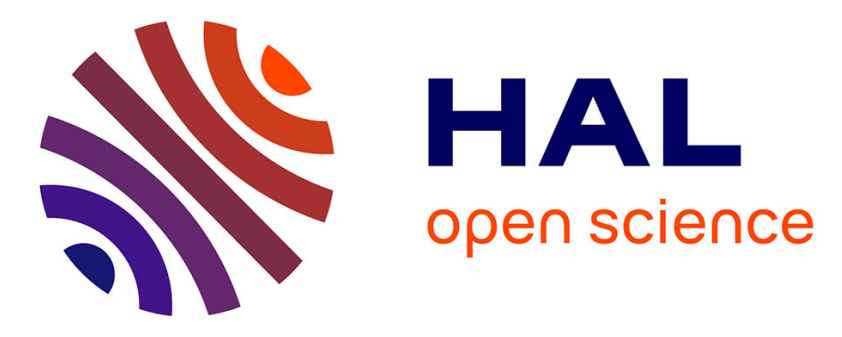

\title{
How can we make pregnancy safe for women with Turner syndrome?
}

Bruno Donadille, Valérie Bernard, Sophie Christin-Maitre

\section{To cite this version:}

Bruno Donadille, Valérie Bernard, Sophie Christin-Maitre. How can we make pregnancy safe for women with Turner syndrome?. American Journal of Medical Genetics Part C: Seminars in Medical Genetics, 2019, Proceedings of the Turner Syndrome Resource Network Symposium, 181 (1), pp.34-41. 10.1002/ajmg.c.31682 . hal-02180018

\section{HAL Id: hal-02180018 https://hal.sorbonne-universite.fr/hal-02180018}

Submitted on 11 Jul 2019

HAL is a multi-disciplinary open access archive for the deposit and dissemination of scientific research documents, whether they are published or not. The documents may come from teaching and research institutions in France or abroad, or from public or private research centers.
L'archive ouverte pluridisciplinaire HAL, est destinée au dépôt et à la diffusion de documents scientifiques de niveau recherche, publiés ou non, émanant des établissements d'enseignement et de recherche français ou étrangers, des laboratoires publics ou privés. 
i. Title

How can we make pregnancy safe for women with Turner syndrome?

\section{ii. Authors}

Donadille, B. ${ }^{1 *}$; Bernard, V. ${ }^{1 *}$; Christin-Maitre, S. ${ }^{1,2}$

iii. Institutional affiliations

1 - Endocrinology Department, Saint Antoine Hospital, Centre de Référence des Maladies

Endocrines Rares de la Croissance et du développement, Filière FIRENDO, ENDO-ERN, Assistance publique-Hôpitaux de Paris, 75571 Paris, France.

2 - Inserm, UMR-S933, Paris, France \& Sorbonne Université, 75006 Paris.

* Authorship note: Donadille, B. and Bernard, V. are both co-first authors

\section{iv. Grant number}

NA 


\title{
v. Abstract and keywords
}

\begin{abstract}
Pregnancy is a crucial issue in patients with Turner syndrome (TS). Although natural pregnancies have been reported in $4-7 \%$ of TS patients, most women will need assisted reproductive technologies (ART) with oocyte donation. The main issue is the maternal mortality rate that is higher than in the general population. It is related to cardiovascular anomalies and particularly aortic dissection.
\end{abstract}

Turner syndrome, per se, is not a contraindication for pregnancy, but a multidisciplinary screening is mandatory before initiating a pregnancy. It includes repeated aortic diameters evaluation, blood pressure measurement and biological testing evaluating thyroid and liver functions, as well as blood glucose level. In order to make the pregnancy safe, contraindications of pregnancy should be respected and identification of high-risk patients for cardiovascular events should be performed. Hypertension and pre-eclampsia prevention may benefit from beta-blockers and aspirin, respectively.

Collaborations between endocrinologists, cardiologists and obstetricians are mandatory during pregnancy and even in the post-partum period. Counseling the patients about the risks of pregnancy, screening them and spreading the international guidelines to physicians taking care of patients with TS are the three pillars of a safe pregnancy.

\section{Keywords}

Turner syndrome; Fertility; Pregnancy; Aortic dissection; Mortality 


\section{vi. Main text}

\section{Introduction}

Turner syndrome (TS) affects about 1 in 2,500 newborn girls. It is a chromosomal disorder that affects phenotypic females who have one intact X chromosome and complete or partial absence of the second sex chromosome in association with some clinical conditions. The most common abnormalities are growth failure (95-100\% of cases), hypertension (50\%), elevated hepatic enzymes (50-80\%) and primary ovarian insufficiency (POI) (95\%) (Gravholt et al., 2017).

For the majority of women with TS, in vitro fertilization (IVF) with oocyte donation represents, since the 1980s (Lutjen et al., 1984), the only way to be pregnant. Those pregnancies are however associated with many maternal, fetal and obstetrical complications (Bodri et al., 2006; Alvaro Mercadal et al., 2011; Chevalier et al., 2011; Hagman et al., 2013; Gravholt et al., 2017).

Since 2007, several recommendations and guidelines have been proposed for the management of patients with TS before and during pregnancy (Bondy et al., 2007; Cabanes et al., 2010; Gravholt et al., 2017). It is now established that pregnancies of TS women should be carefully monitored by a multidisciplinary team including maternal-fetal medicine specialists with expertise in managing patients with TS (Gravholt et al., 2017). This paper will focus on the main pregnancy risks that have to be taken into account to make pregnancies safer in TS. The most important are cardiovascular complications, including aortic dilatation and dissection, gestational hypertension and preeclampsia. Furthermore, on the maternal side, if cardiovascular complications are most dangerous, liver diseases, diabetes and thyroid dysfunction may further complicate the pregnancy in patients with TS.

\section{Different types of pregnancies in TS patients}

Primary ovarian insufficiency is a classic feature of TS. Haploinsufficiency of X pseudoautosomal genes leads to an acceleration of follicular atresia (Modi, 2003) and, in most cases, to gonadal failure with primary amenorrhea. However, in $5-20 \%$ of girls with TS, follicles are still 
present and allow for spontaneous menarche (Pasquino et al., 1997; Hovatta, 1999; Hreinsson et al., 2002). Ovarian status is highly associated with the TS karyotype. In the Turner syndrome life course project, primary amenorrhea was observed in $88.5 \% ; 41.7 \%$; $78.3 \%$ and $81.4 \%$ of patients with $45, \mathrm{X}$; 45,X/46,XX mosaicism; Xq isochromosome and 45,X/46,XY mosaicism, respectively (CameronPimblett et al., 2017). In a longitudinal study of 120 Turner syndrome patients in Denmark, the majority of women with 45,X/46,XX mosaic karyotype had ongoing ovarian function in early adulthood (Lunding et al., 2015). According to the remaining ovarian function, three types of pregnancies have been described in TS patients: natural pregnancies, pregnancies after in vitro fertilization (IVF) without oocyte donation, and those obtained after IVF with oocyte donation.

Few studies have reported natural pregnancies in women with TS (Birkebaek et al., 2002; Bryman et al., 2011; Hadnott et al., 2011; Bernard et al., 2016). The first study, from Denmark (Birkebaek et al., 2002) was based on a national cytogenetic central register. It included 412 women with TS and the rate of natural pregnancies was 7.6\%. The second study from Sweden (Bryman et al., 2011), included 482 TS patients and evaluated both natural pregnancies and pregnancies issued from ART. The prevalence of natural pregnancies was 4.8\%. Another study including 276 TS women from the United States (Hadnott et al., 2011) found a lower prevalence of natural pregnancies, reaching only $1.8 \%$. Our group performed a study including 480 French adult patients with TS and reported a natural pregnancy rated of 5.6\% (Bernard et al., 2016). Eighteen patients (3.8\%) had at least one live born child. The two predictive factors which correlated with occurrence of a natural pregnancy were spontaneous menarche and mosaic karyotype (Bernard et al., 2016). However, 2 patients with a full 45,X karyotype had natural pregnancies. This is probably due to the fact that their ovarian karyotypes were different from the lymphocytes' karyotype. These four studies illustrate the fact that natural pregnancies in women with TS are not as rare as previously thought.

Few data are available concerning pregnancies in women with TS issued from IVF without oocyte donation. Ovarian stimulation is not often performed as those patients usually have a decreased ovarian reserve, with low AMH levels and low antral follicle count (Lunding et al., 2015). However, several cases of ovarian stimulation have been described in patients with Turner syndrome in order to 
preserve their fertility(Balen et al., 2010; Oktay et al., 2014). Recently, Talaulikar et al. reported ovarian stimulation in 7 TS patients. The mean oocyte retrieval rate was $9 \pm 3.16$ oocytes. However, no pregnancy has been reported so far after using cryopreserved oocytes in TS patients (Talaulikar et al., 2018).

Most pregnancies in TS patients are obtained after IVF with oocyte donation as POI concerns $95 \%$ of TS patients. The clinical pregnancy rates using this technique in TS women vary between 16 and 40\% (Gravholt et al., 2017). Those results are consistent with pregnancy rates in women without TS, undergoing oocyte donation. However, the rate of miscarriage is elevated. Pregnancy losses are most often due to the presence of a hypoplastic or bicornuate uterus and a thinner endometrial lining than that typically seen in pregnant women without Turner syndrome (Khastgir et al., 1997). Another explanation could be a high prevalence of autoimmunity disorders in these patients (Abir et al.,2001). The rate of complication for pregnancies obtained after oocyte donation is high. For instance, in a French study performed in 82 patients with TS, only $40.2 \%$ completed their pregnancy without complications (Chevalier et al., 2011).

\section{Cardiovascular risk in patients with TS outside of pregnancy}

Several studies have shown an increased cardiovascular risk in patients with Turner syndrome, even outside of pregnancy. One of the largest study from UK including 3439 TS patients reported a standardized mortality rate (SMR) of 3.0 (95\%CI: 2.7-3.4). It was higher in patients with aortic aneurysm (SMR: 23.6) or aortic valve disease (SMR: 17.9). Circulatory diseases accounted for nearly half (41\%) of excess mortality (Schoemaker et al., 2008). Stockholm et al. observed 69 deaths among the 781 TS patients from the Danish cytogenetic register. Their calculated SMR was $2.86(95 \% \mathrm{CI}$ 2.2-3.5). It was higher in patients with congenital malformations (SMR: 24.09) (Stochholm et al., 2006) and congenital heart diseases are frequent in women with TS, as they occur in nearly half of patients with TS (Gravholt et al., 2017). The prevalence of bicuspid aortic valves is $15-30 \%$ and therefore 30-60 times more frequent than among the general female population. The prevalence of aortic coarctation is 7-18\% (Gravholt et al., 2017). Congenital heart disease are known congenital risk 
factors for aortic dilatation and dissection (Mortensen et al., 2009). Furthermore, hypertension is an acquired risk factor for aortic dilatation. It is also very prevalent, as high blood pressure has been reported in $60 \%$ of TS patients in some studies from northern Europe (De Groote, 2015).

\section{Physiology of the cardiovascular system during normal pregnancies}

Pregnancy physiology is associated with increases in maternal volemia, heart rate, blood pressure, stroke volume and cardiac output. Gravidic variations in female sex hormone levels play a critical role in pregnancy-induced cardiac adaptation: progesterone surges appear to initiate a ventricular hypertrophic signaling and estradiol in late pregnancy seems to initiate a post-partum cardiac remodeling (Chung et al., 2014). Those hormonal modifications may induce vascular structure modifications potentially resulting in aortic media injury. Furthermore, wall tension and intimal shear forces increase during the first and second trimesters, being maximal during the last trimester.

During delivery in a normal pregnancy, a $30-50 \%$ increase in cardiac output and large hemodynamic changes may occur. Indeed, each contraction forces an additional 300-500 $\mathrm{ml}$ of venous blood back into the central venous system (Coulon, 2015). Furthermore, during the second stage of labor, blood pressure and heart rate increase due to the pushing efforts and the Valsalva maneuvers. After placental delivery, $500 \mathrm{ml}$ of blood is diverted from the utero-placental bed back into the maternal circulation, which in turn increases central venous pressures, ventricular preload and cardiac output (Coulon, 2015). Arterial microdissections during labor of a vaginal delivery may be associated with dramatic late postpartum aortic acute events.

In the general population, cardiovascular diseases complicate $1-3 \%$ of all pregnancies. It represents the second commonest cause of maternal mortality (Chang et al., 2003). However, aortic dissection in the general population remains a very rare event. In the maternal mortality report in the UK, covering maternal deaths between 2003 and 2005, aortic dissection accounted for seven out of 53 cardiac deaths (McClure et al., 2011). In the latest version, arterial aneurysms induced 10 deaths during pregnancy. However, ruptured splenic artery aneurysms were involved. No case of thoracic aortic dissection was 
reported (Knight $\mathrm{M}$ et al., 2018). In a study from Netherlands, nearly half of maternal cardiovascular deaths were related to an aortic dissection (Huisman et al., 2013). Half of the acute aortic dissection in women under the age of 40 occurs during pregnancy or peripartum period (Williams et al., 1988).

\section{What are the cardiovascular complications in pregnant patients with TS?}

Several studies have reported cardiovascular risk in TS women during natural pregnancies or during pregnancies obtained after oocyte donation. Significant morbidities have been reported, such as pregnancy-associated hypertensive disorders (PAHD), including preeclampsia, as well as hemolysis elevated liver enzyme and low platelets (HELLP) syndrome (Gravholt et al., 2017). The overall rate of PAHD is around $30-50 \%$ of pregnancies with TS. Furthermore, several case reports of aortic dissection have been described during pregnancy in TS patients ( $\underline{\text { Table I) }}$ (Garvey et al., 1998; Karnis et al., 2003; Ohl et al., 2008; Boissonnas et al., 2009; Chevalier et al., 2011; Carlson et al., 2012). Unfortunately, exhaustive registries of pregnancies in patients with TS are not available. Therefore, the prevalence of cardiovascular events in pregnant patients with TS is difficult to evaluate.

\subsection{Cardiovascular complications in pregnancies obtained after oocyte donation}

Half of the existing donor-egg programs in the United States were surveyed in 1997. They included 146 Turner patients and 101 pregnancies were observed (Karnis et al., 2003). One patient died from an aortic rupture while awaiting oocyte donation. No deaths were reported during pregnancy. The National Institute of Health reported the outcomes of ART pregnancies in TS patients (Karnis et al., 2003; Hadnott et al., 2011; Practice Committee of American Society For Reproductive Medicine, 2012). Out of the four deaths in (Karnis et al., 2003), one patient had a twin pregnancy, a marked aortic dilatation and she presented with pre-eclampsia.

In Sweden, Hagman et al studied a country-based registry, including 124 pregnant women out of 502 women with TS, between 1973 and 2010. Cardiovascular events occurred during pregnancy or within one year after the delivery (HR 5.78; 95\%CI 1.94-17.24). Aortic aneurysm occurred in 11/502 
(2.2\%) women and in 3 women during pregnancy. Only $63 \%$ had cardiovascular examination before pregnancy. Hypertension was observed in $35 \%$ of pregnancies and pre-eclampsia occurred in $20.5 \%$. Life-threatening complications occurred in $3.3 \%$ of pregnancies. However, no death was observed (Hagman et al, 2011; Hagman et al., 2013).

A French nationwide multicenter study published in 2011 (Chevalier et al., 2011), included all TS patients with pregnancies obtained after oocyte donation. Two out of the 93 patients $(2.2 \%)$ died of aortic dissection. Both deaths occurred after delivery by cesarean section at 38 wk gestation: the first in the early post-aortoplasty period (Boissonnas et al., 2009), the second died one week after delivery (Ohl, 2008). The rate of pregnancy-associated hypertensive disorders reached $37.8 \%$ of those pregnancies. Severe pre-eclampsia occurred in $54.8 \%$ of those cases and HELLP syndrome occurred in one patient. Prematurity was observed in $38.3 \%$ (p 0.01) and one fetal demise was linked to eclampsia (Chevalier et al., 2011).

\subsection{Cardiovascular complications in natural pregnancies of women with TS}

Few studies have evaluated the outcome of natural pregnancies in TS patients. So far, 2 cases of aortic dissection have been reported in the literature during the third trimester of natural pregnancies (Hagman et al., 2011). Two other cases have been reported, respectively 2 and 17 years after the pregnancy ( Carlson et al., 2012). The relationship between the pregnancy and the aortic dissection in those cases is not demonstrated. In a cohort including 480 women, pregnancy-induced maternal hypertensive disorders occurred only in four cases (13.3\% of the 30 achieved pregnancies), including two cases of mild pre-eclampsia (6.7\%) (Bernard et al., 2016). One of the patients with pre-eclampsia had an aortic bicuspid valve. Neither aortic dissection nor cardiac complication was observed in any of the pregnant women during pregnancy or post-partum. Hadnott et al also reported 7 achieved natural pregnancy in TS patients without maternal cardiovascular complication (Hadnott et al., 2011). Therefore, natural pregnancies seem to be less complicated than pregnancies obtained after oocyte donation in TS women. One hypothesis may rely on the younger age of patients with TS and natural 
pregnancies over the mean age of pregnancies obtained after oocyte donation. Another hypothesis is that patients achieving natural pregnancies have a less severe phenotype of the syndrome than those requiring oocyte donations, especially the cardiovascular phenotype. Indeed, one major predictive factor of NP is the karyotype with mosaicism, which is associated with a less severe phenotype than X monosomy. Moreover, it is known that oocyte donation is an independent risk factor for pregnancy complications (Younis et al., 2015). Another potential explanation relies on the impact of high estrogen levels on the arterial wall. However, during oocyte donation, patients on hormonal replacement therapy have a lower estradiol serum level than during ovarian stimulation with gonadotropins.

\section{How to make pregnancies safe in TS patients?}

\subsection{Identify high risk patients of cardiovascular events}

Published international guidelines recommend aortic diameter measurements at each anatomic specific levels of the aortic root, perpendicular to vessel wall, from inner edge to inner edge, at the following levels: aortic annulus, Valsalva sinuses, sino-tubular junction, tubular ascending aorta, aortic cross and descending aorta (Kawel-Boehm et al., 2015). Before the report of Karnis et al. in 2003, few women with TS had a cardiovascular examination before or during pregnancy. In the two largest studies, cardiovascular evaluation had not been optimal as screening before pregnancy with transthoracic echography (TTE) or cardiac magnetic resonance (CMR) had been performed in 38 and 49\% of cases, respectively from 93 and 106 women (Karnis et al., 2003; Chevalier et al., 2011). The lack of appropriate screening prior to pregnancy could be the main cause of aortic dissection. The current recommendation is to perform cardiac and aortic imaging (TTE, CMR) within 2 years before planned pregnancy with oocyte donation (Gravholt et al., 2017).

It is usually recommended to index the aortic diameter to the body surface area (BSA), which defines an aortic size index (ASI). In one of the two French patients who died secondary to dissection (Ohl, 2008), the initial diameter before pregnancy had not been indexed to BSA and therefore the 
cardiovascular risk had been initially underestimated. Furthermore, Boissonnas et al. studied 18 women with TS requesting oocyte donation. All pre-pregnancy cardiac evaluations had been considered as reassuring (Boissonnas et al., 2009). However, when a cardiologist familiar with TS reevaluated these women, seven were diagnosed with a cardiac abnormality and therefore denied oocyte donation. Because BSA takes into account the patient's weight, a value of ASI may be distorted before or during pregnancy, especially in obese patients. In such cases, absolute values of aortic diameter may be useful. An ASI level higher than $25 \mathrm{~mm} / \mathrm{m} 2$ has been associated with a risk of dissection in adult patients (Matura et al., 2007). However, the individual prediction of dissection remains very difficult.

Regarding karyotype, patients carrying a complete 45,X monosomy should be monitored closely, as congenital cardiovascular malformations are more frequent. A 45,X karyotype was present in $80 \%$ (39/49) of the published cases of dissection (Carlson et al., 2007). However, patients with mosaic karyotypes are not exempted of dissection, as illustrated in the US registry (Carlson et al., 2012).

Among the risk factors of aortic dilatation, hypertension is an acquired risk factor that should be searched for in order to prevent aortic dilatation, which precludes aortic dissection. Therefore, blood pressure should be evaluated at least each month during pregnancy and its level should be maintained below $135 / 85 \mathrm{mmHg}$. In the general population, risk factors of pre-eclampsia and gestational hypertensive disorders are: a previous history of pre-eclampsia, nulliparity, older age, obesity, diabetes, renal insufficiency, antiphospholipid syndrome, and previous history of miscarriage (Abalos et al., 2001). Higher risk of hypertensive disorder with oocyte donation in TS women may be related to an abnormal placenta (Gravholt et al., 2017) and therefore antiplatelet aggregation may be beneficial. The use of low-dose aspirin (75-81 mg) may be considered in pregnant women with TS (Gravholt et al., 2017). Aspirin therapy is recommended for women at increased risk for preeclampsia which would include women with TS. These patients may have poor placental vascular invasion, but that has not been proven. There is no data so far showing that aspirin will reduce the rate of cardiovascular events in any population, as the mechanism of action is likely at the placental level and will not impact maternal systemic vasculature. 
Since the risk of dissection is suspected to be 5 times higher during a multiple gestation (Mortensen et al., 2012), it is crucial that women receiving ART by oocyte donation have a single embryo transfer.

A recent French study has assessed pregnancy outcome in TS since 2009. This timing has been chosen as national French guidelines have been published in 2010 (Cabanes et al., 2010). Fourteen oocyte donation centers recruited 103 patients with TS (Cadoret et al., 2018). One hundred and seventy clinical pregnancies were followed, including 35 natural pregnancies and 130 obtained after oocyte donation. No maternal death occurred. Two stillbirths and one intra-uterine fetal death were reported. A pre-conceptional assessment and a gravidic cardiological follow-up were carried out in $74 \%$ of cases. Post-partum cardiac ultrasonographies were performed in $45 \%$ of pregnancies. Hypertension and pre-eclampsia rates reached $19 \%$ and $8 \%$ of all pregnancies, respectively. This study reports a higher rate of cardiovascular follow-up than in the previous study published by Chevalier et al. in 2011. Interestingly, the rate of cardiovascular events was much lower. This could be related to the potential benefits of spreading and applying cardiovascular guidelines.

\subsection{Respect the contra-indication of a pregnancy in patients with TS}

Pregnancy should be avoided in case of an ascending indexed aortic diameter $>25 \mathrm{~mm} / \mathrm{m} 2$ alone or between 20 to $25 \mathrm{~mm} / \mathrm{m} 2$ with associated risk factors for dissection, such as a bicuspid aortic valve, an aortic coarctation and an uncontrolled hypertension. In case of an aortic dilatation with an ASI between 20 and $25 \mathrm{~mm} / \mathrm{m}^{2}$ detected prior to pregnancy, no study to date has answered the question whether elective aortic surgery should be performed before initiating a pregnancy. A history of aortic surgery or aortic dissection is still a contraindication for pregnancy. In such cases, patients should be offered surrogacy and adoption as alternatives for having a family (Practice Committee of American Society For Reproductive Medicine, 2012). 


\subsection{Close cardiovascular follow-up during pregnancy and the post-partum period}

The rhythm of aortic diameter evaluation during pregnancy depends on the initial diameter of the aorta. In all cases, at least one TTE is recommended at 20 weeks of pregnancy. If indexed aortic diameter increases during pregnancy and becomes higher than $20 \mathrm{~mm} / \mathrm{m}^{2}$, in the presence of known risks factors such as hypertension, aortic bicuspid valve, aortic coarctation, previous dissection, the patients should be regularly monitored. In such cases, TTE should be performed at 4 weeks intervals during pregnancy and during the first month in the post-partum period. Even when dilatation is not detected in the first two trimesters, it should be stressed that dissection presents in the third trimester or postpartum (Lin et al., 2016). CMR without gadolinium injection should be considered in case of deficient visualization of the aorta or when the aortic diameter increases.

When an aortic dilatation is discovered during pregnancy, as angiotensin receptor blockers cannot be prescribed during pregnancy, beta-blockers may be used. However, no study has proven to date, a protective role of this treatment in reducing aortic dilatation during pregnancy. This recommendation is mainly based on studies performed in pregnant patients with Marfan syndrome (Kuperstein et al., 2017).

If a significant progression of aortic dilatation occurs before the fetus is viable, surgical aortoplasty is indicated. If the fetus is viable, cesarean delivery followed by aortic surgery is recommended. During pregnancy, prophylactic surgery may be considered in the case of a dilated aorta $>25 \mathrm{~mm} / \mathrm{m}^{2}$ with rapid progression $>3 \mathrm{~mm}$ (Gravholt et al., 2017). If a pre-existing valve surgery has been performed, risks of thrombosis or bleeding in case of mechanical valve exist (Silberbach et al., 2018). If a bioprosthetic valve is present, the risk of thrombosis or bleeding is lower.

Every physician following a pregnant woman with TS should remember that aortic dissection may occur even without previous dilatation (Practice Committee of American Society For Reproductive Medicine, 2012). As this is a life-threatening medical emergency with high rates of mortality, any patient with acute and severe chest pain should seek prompt medical advice. In the US dissection register (Carlson, 2012), taking care of such women was performed after a delay of $24 \mathrm{~h}$, in a large number of cases $(68 \%)$. 


\subsection{Optimization of the mode of delivery}

In order to make the pregnancy safe, the mode of delivery should be optimized. Pregnant women with aortic dilatation should deliver in a hospital where cardiothoracic surgery is available. Like in the general population, vaginal delivery is initially preferred except in presence of a significant maternofetal disproportion and a significant aortic dilatation. Cesarean section is preferred for women with aortic diameter rapidly increasing or exceeding $25 \mathrm{~mm} / \mathrm{m} 2$. Between $20-25 \mathrm{~mm} / \mathrm{m}^{2}$, a vaginal delivery with epidural anesthesia is possible but the patient should be informed that a cesarean section may occur (Gravholt et al., 2017), as a cesarean section allows limitation of blood pressure and cardiac output variations. In the presence of an ASI $>20 \mathrm{~mm} / \mathrm{m}^{2}$, post-partum monitoring within the hospital is indicated for at least 48 hours (Gravholt et al., 2017). Hence, those high-risk pregnancies should be followed in a specialized tertiary center and choice of delivery route management should be discussed by a multidisciplinary team (Silberbach et al., 2018).

\subsection{Biological evaluation of the thyroid, the liver, the kidneys and diabetes}

Hypothyroidism due to Hashimoto thyroiditis is the most prevalent autoimmune disorder found in patients with TS (El-Mansoury et al., 2005). It may begin in early childhood, and its prevalence increases with age (Mortensen et al., 2009). The incidence of Graves' disease in young TS patients is around 2-3\% (Bakalov et al. 2012; Aversa et al. 2015). The incidence of thyroid dysfunction is high both during spontaneous pregnancies or those obtained after oocyte donation, in TS patients. Rates of thyroid dysfunction range from 7 to $44 \%$ (Hagman et al. 2013; Bernard et al. 2016). Screening patients with TS for thyroid disease before pregnancy, should prevent complications from uncontrolled overt maternal hypothyroidism, as described in the general population, such as preeclampsia and gestational hypertension, preterm delivery, including very preterm delivery, low birth weight, postpartum hemorrhage, perinatal morbidity and mortality, as well as neuropsychological or cognitive impairment in the child (Männistö et al., 2013). 
Liver function should be monitored closely before and during pregnancy, in women with TS. Before pregnancy, hepatic fibrosis should be screened, as cirrhosis with portal hypertension and esophageal variceal bleeding is a contraindication to pregnancy (Cabanes et al., 2010). It is recommended to repeat liver function tests yearly, before oocyte donation. During pregnancy, liver function needs to be monitored. In the French study by Chevalier et al., a patient died of gravidic cholestasis (Ohl, 2008). In mild cases of preeclampsia, there is a mild elevation of serum AST/ALT/Alkaline phosphatase. During HELLP syndrome, serum aminotransferases are more than ten times elevated, and unconjugated hyperbilirubinemia may be present due to hemolysis (Kelly, 2018).

The risk of both type 1 and type 2 diabetes mellitus is highly increased in patients with TS (Bakalov et al., 2008; Schoemaker et al., 2008). Various abnormalities in glucose homeostasis are reported in these patients, including insulin resistance, decreased insulin secretion and impaired glucose tolerance due to both reduced first-phase insulin release and diminished $\beta$ - pancreatic cell responsiveness (Caprio et al., 1991;Bakalov et al., 2004; Hjerrild et al., 2011). These metabolic abnormalities could be amplified during pregnancy and lead to a high risk of gestational diabetes in women with TS. However, in a clinical study concerning spontaneous pregnancies in women with TS, the prevalence of gestational diabetes was not elevated (3\%)(Bernard et al., 2016). Concerning pregnancies of patients with TS after oocyte donation, the rate of gestational diabetes is much higher, around 10\% (Hagman et al., 2013). So, women with TS should be screened carefully prior to and during pregnancy to ensure gestational diabetes is rapidly diagnosed and treated.

In order to make a pregnancy safe in a patient with TS, multidisciplinary evaluations are mandatory, including several physicians such as endocrinologists, cardiologists, radiologists and gynecologists. Table II reports a check-list of the different evaluations to be performed prior to a pregnancy in a patient with TS. The preconceptional visit is a crucial point in the care of every patient with TS. 


\section{Conclusion}

Several international and national guidelines have been published in recent years, recommending pre-pregnancy evaluation and careful monitoring during pregnancy and in the postpartum period in women with TS (Cabanes, 2010; Practice Committee of American Society For Reproductive Medicine, 2012; Gravholt et al., 2017). The dissemination of those recommendations should lower the prevalence of complications during pregnancies in patients with TS. However, as the quality of evidence of some of the recommendations from those guidelines have been classified as moderate, low or even very low, studies are still necessary in order to further reduce the risks of pregnancy in patients with TS.

In summary, cardiovascular risks in Turner syndrome during pregnancy are high and therefore cardiovascular pre-pregnancy evaluations as well as follow-up during pregnancy are of utmost importance. A multidisciplinary approach to care of patients with TS seeking a pregnancy, during the pregnancy and during the post-partum period is absolutely necessary. 


\section{vii. Aknowledgments}

The authors would like to thank the patients with TS followed in our Unit.

The authors acknowledge the symposium grantors who made this symposium possible:

. National Institutes of Child Health and Development (NICHD R13 HD096857-01),

. Patient-Centered Outcomes Research Institute (PCORI) Eugene Washington PCORI Engagement Award (\#10460).

viii. Legends

Table I- Summary of published pregnancies with aortic dissection in women with TS

BAV: bicuspid aortic valve; Type A/B: Stanford dissection type (type A: ascending aorta; type B: descending aorta); ART/DO: assisted reproductive technology/oocyte donation.

Table II- Check list of exams to be performed prior to a pregnancy in TS patients

BMI: body mass index [weight $\left.(\mathrm{Kg}) / \mathrm{height}^{2}(\mathrm{~m})\right]$; BSA: body surface area (calculated using the Dubois \& Dubois formula); ASI: aortic size index (aortic diameter at the level of the tubular ascending aorta/BSA; $N<20 \mathrm{~mm} / \mathrm{m}^{2}$ ); CMR: cardiac/cardiovascular magnetic resonance. 


\section{ix. $\quad$ References}

Abalos, E., Duley, L., Steyn, D. W., \& Henderson-Smart, D. J. (2001). Antihypertensive drug therapy for mild to moderate hypertension during pregnancy. The Cochrane Database of Systematic Reviews, (2), CD002252. https://doi.org/10.1002/14651858.CD002252

Abir, R., Fisch, B., Nahum, R., Orvieto, R., Nitke, S., \& Ben Rafael, Z. (2001). Turner's syndrome and fertility: current status and possible putative prospects. Human Reproduction Update, 7(6), 603-10. Retrieved from http://www.ncbi.nlm.nih.gov/pubmed/11727869

Alvaro Mercadal, B., Imbert, R., Demeestere, I., Englert, Y., \& Delbaere, A. (2011). Pregnancy outcome after oocyte donation in patients with Turner's syndrome and partial X monosomy. Human Reproduction (Oxford, England), 26(8), 2061-8. https://doi.org/10.1093/humrep/der166

Aversa, T., Lombardo, F., Valenzise, M., Messina, M. F., Sferlazzas, C., Salzano, G.,Wasniewska, M. (2015). Peculiarities of autoimmune thyroid diseases in children with Turner or Down syndrome: an overview. Italian Journal of Pediatrics, 41(1), 39. https://doi.org/10.1186/s13052-015-0146-2

Bakalov, V. K., Cooley, M. M., Troendle, J., \& Bondy, C. A. (2004). The prevalence of diabetes mellitus in the parents of women with Turner's syndrome. Clinical Endocrinology, 60(2), 272. Retrieved from http://www.ncbi.nlm.nih.gov/pubmed/14725692

Bakalov, V. K., Gutin, L., Cheng, C. M., Zhou, J., Sheth, P., Shah, K., Bondy, C.A. (2012). Autoimmune disorders in women with turner syndrome and women with karyotypically normal primary ovarian insufficiency. Journal of Autoimmunity, 38(4), 315-21. https://doi.org/10.1016/j.jaut.2012.01.015

Balen, A. H., Harris, S. E., Chambers, E. L., \& Picton, H. M. (2010). Conservation of fertility and oocyte genetics in a young woman with mosaic Turner syndrome. BJOG: An International Journal of Obstetrics and Gynaecology. https://doi.org/10.1111/j.1471-0528.2009.02423.x

Bernard, V., Donadille, B., Zenaty, D., Courtillot, C., Salenave, S., CMERC Center for Rare Disease. (2016). Spontaneous fertility and pregnancy outcomes amongst 480 women with Turner 
syndrome. Human Reproduction (Oxford, England), 31(4), 782-8. https://doi.org/10.1093/humrep/dew012

Birkebaek, N. H., Crüger, D., Hansen, J., Nielsen, J., \& Bruun-Petersen, G. (2002). Fertility and pregnancy outcome in Danish women with Turner syndrome. Clinical Genetics, 61(1), 35-9. Retrieved from http://www.ncbi.nlm.nih.gov/pubmed/11903353

Bodri, D., Vernaeve, V., Figueras, F., Vidal, R., Guillén, J. J., \& Coll, O. (2006). Oocyte donation in patients with Turner's syndrome: a successful technique but with an accompanying high risk of hypertensive disorders during pregnancy. Human Reproduction (Oxford, England), 21(3), 82932. https://doi.org/10.1093/humrep/dei396

Boissonnas, C. C., Davy, C., Bornes, M., Arnaout, L., Meune, C., Tsatsatris, V., Jouannet, P. (2009). Careful cardiovascular screening and follow-up of women with Turner syndrome before and during pregnancy is necessary to prevent maternal mortality. Fertility and Sterility, 91(3), 929.e5-7. https://doi.org/10.1016/j.fertnstert.2008.09.037

Bondy C.A et al. (2007). Care of girls and women with Turner syndrome: A guideline of the Turner Syndrome Study Group. The Journal of Clinical Endocrinology and Metabolism, 92(1), 10-25. https://doi.org/10.1210/jc.2006-1374

Bryman, I., Sylvén, L., Berntorp, K., Innala, E., Bergström, I., Hanson, C., Landin-Wilhelmsen, K. (2011). Pregnancy rate and outcome in Swedish women with Turner syndrome. Fertility and Sterility, 95(8), 2507-2510. https://doi.org/10.1016/j.fertnstert.2010.12.039

Cabanes, L., Chalas, C., Christin-Maitre, S., Donadille, B., Felten, M. L., Gaxotte, V., Zénaty, D. (2010). Turner syndrome and pregnancy: clinical practice. Recommendations for the management of patients with Turner syndrome before and during pregnancy. European Journal of Obstetrics, Gynecology, and Reproductive Biology, 152(1), 18-24. https://doi.org/10.1016/j.ejogrb.2010.05.019

Cadoret, F., Parinaud, J., Bettiol, C., Pienkowski, C., Letur, H., Ohl, J., Parant, O. (2018). Pregnancy 
outcome in Turner syndrome: A French multi-center study after the 2009 guidelines. European Journal of Obstetrics, Gynecology, and Reproductive Biology, 229, 20-25. https://doi.org/10.1016/j.ejogrb.2018.08.005

Cameron-Pimblett, A., La Rosa, C., King, T. F. J., Davies, M. C., \& Conway, G. S. (2017). The Turner syndrome life course project: Karyotype-phenotype analyses across the lifespan. Clinical Endocrinology. https://doi.org/10.1111/cen.13394

Caprio, S., Boulware, S., Diamond, M., Sherwin R. S., Carpenter, T. O., Rubin, K.,Tamborlane, W. V. (1991). Insulin Resistance: An Early Metabolic Defect of Turner's Syndrome*. The Journal of Clinical Endocrinology \& Metabolism, 72(4), 832-836. https://doi.org/10.1210/jcem-72-4-832

Carlson, M., Airhart, N., Lopez, L., \& Silberbach, M. (2012). Moderate aortic enlargement and bicuspid aortic valve are associated with aortic dissection in Turner syndrome: report of the international turner syndrome aortic dissection registry. Circulation, 126(18), 2220-6. https://doi.org/10.1161/CIRCULATIONAHA.111.088633

Carlson, M., \& Silberbach, M. (2007). Dissection of the aorta in Turner syndrome: two cases and review of 85 cases in the literature. Journal of Medical Genetics, 44(12), 745-9. https://doi.org/10.1136/jmg.2007.052019

Chang, J., Elam-Evans, L. D., Berg, C. J., Herndon, J., Flowers, L., Seed, K. A., \& Syverson, C. J. (2003). Pregnancy-related mortality surveillance--United States, 1991--1999. Morbidity and Mortality Weekly Report. Surveillance Summaries (Washington, D.C.: 2002), 52(2), 1-8. Retrieved from http://www.ncbi.nlm.nih.gov/pubmed/12825542

Chevalier, N., Letur, H., Lelannou, D., Ohl, J., Cornet, D., Chalas-Boissonnas, C., French Study Group for Oocyte Donation. (2011). Materno-fetal cardiovascular complications in Turner syndrome after oocyte donation: insufficient prepregnancy screening and pregnancy follow-up are associated with poor outcome. The Journal of Clinical Endocrinology and Metabolism, 96(2), E260-7. https://doi.org/10.1210/jc.2010-0925 
Chung, E., \& Leinwand, L. A. (2014). Pregnancy as a cardiac stress model. Cardiovascular Research, 101(4), 561-70. https://doi.org/10.1093/cvr/cvu013

Coulon, C. (2015). Thoracic aortic aneurysms and pregnancy. Presse Medicale (Paris, France: 1983), 44(11), 1126-35. https://doi.org/10.1016/j.lpm.2015.02.024

De Groote, K., Demulier, L., De Backer, J., De Wolf, D., De Schepper, J., T'sjoen, G., \& De Backer, T. (2015). Arterial hypertension in Turner syndrome: a review of the literature and a practical approach for diagnosis and treatment. Journal of Hypertension, 33(7), 1342-51. https://doi.org/10.1097/HJH.0000000000000599

El-Mansoury, M., Bryman, I., Berntorp, K., Hanson, C., Wilhelmsen, L., \& Landin-Wilhelmsen, K. (2005). Hypothyroidism is common in turner syndrome: results of a five-year follow-up. The Journal of Clinical Endocrinology and Metabolism, 90(4), 2131-5. https://doi.org/10.1210/jc.2004-1262

Garvey, P., Elovitz, M., \& Landsberger, E. J. (1998). Aortic dissection and myocardial infarction in a pregnant patient with Turner syndrome. Obstetrics and Gynecology, 91(5 Pt 2), 864. Retrieved from http://www.ncbi.nlm.nih.gov/pubmed/9572196

Gravholt, C. H., Andersen, N. H., Conway, G. S., Dekkers, O. M., Geffner, M. E., Klein, K. O et al. (2017). Clinical practice guidelines for the care of girls and women with Turner syndrome: proceedings from the 2016 Cincinnati International Turner Syndrome Meeting. European Journal of Endocrinology, 177(3), G1-G70. https://doi.org/10.1530/EJE-17-0430

Hadnott, T. N., Gould, H. N., Gharib, A. M., \& Bondy, C. A. (2011). Outcomes of spontaneous and assisted pregnancies in Turner syndrome: the U.S. National Institutes of Health experience. Fertility and Sterility, 95(7), 2251-6. https://doi.org/10.1016/j.fertnstert.2011.03.085

Hagman, A., Källén, K., Barrenäs, M.-L., Landin-Wilhelmsen, K., Hanson, C., Bryman, I., \& Wennerholm, U.-B. (2011). Obstetric outcomes in women with Turner karyotype. The Journal of Clinical Endocrinology and Metabolism, 96(11), 3475-82. https://doi.org/10.1210/jc.2011-1421 
Hagman, A., Loft, A., Wennerholm, U.-B., Pinborg, A., Bergh, C., Aittomaki, K., Soderstrom-Anttila, V. (2013). Obstetric and neonatal outcome after oocyte donation in 106 women with Turner syndrome: a Nordic cohort study. Human Reproduction, 28(6), 1598-1609. https://doi.org/10.1093/humrep/det082

Hjerrild, B. E., Holst, J. J., Juhl, C. B., Christiansen, J. S., Schmitz, O., \& Gravholt, C. H. (2011). Delayed $\beta$-cell response and glucose intolerance in young women with Turner syndrome. $B M C$ Endocrine Disorders, 11(1), 6. https://doi.org/10.1186/1472-6823-11-6

Hovatta, O. (1999). Pregnancies in women with Turner's syndrome. Ann Med, 31(2), 106-110. Retrieved from http://www.ncbi.nlm.nih.gov/pubmed/10344582

Hreinsson, JG. Otala, M. Fridström, M. Borgström, B. Rasmussen, C. Lundgvist, M. Tuuri, T. Simberg, N. Mikkola, M. Dunkel, L. Hovatta, O. (2002). Follicles are found in the ovaries of adolescent girls with Turner's syndrome. J Clin Endocrinol Metab, 87(8), 3618-23. https://doi.org/10.1210/jcem.87.8.8753

Huisman, C. M., Zwart, J. J., Roos-Hesselink, J. W., Duvekot, J. J., \& van Roosmalen, J. (2013). Incidence and predictors of maternal cardiovascular mortality and severe morbidity in The Netherlands: a prospective cohort study. PloS One, 8(2), e56494. https://doi.org/10.1371/journal.pone.0056494

Karnis, M. F., Zimon, A. E., Lalwani, S. I., Timmreck, L. S., Klipstein, S., \& Reindollar, R. H. (2003). Risk of death in pregnancy achieved through oocyte donation in patients with Turner syndrome: a national survey. Fertility and Sterility, 80(3), 498-501. Retrieved from http://www.ncbi.nlm.nih.gov/pubmed/12969688

Kawel-Boehm, N., Maceira, A., Valsangiacomo-Buechel, E. R., Vogel-Claussen, J., Turkbey, E. B., Williams, R., Bluemke, D. A. (2015). Normal values for cardiovascular magnetic resonance in adults and children. Journal of Cardiovascular Magnetic Resonance: Official Journal of the Society for Cardiovascular Magnetic Resonance, 17(1), 29. https://doi.org/10.1186/s12968-015$0111-7$ 
Kelly, C., \& Pericleous, M. (2018). Pregnancy-associated liver disease: a curriculum-based review. Frontline Gastroenterology, 9(3), 170-174. https://doi.org/10.1136/flgastro-2017-100924

Khastgir, G., Abdalla, H., Thomas, A., Korea, L., Latarche, L., \& Studd, J. (1997). Oocyte donation in Turner's syndrome: an analysis of the factors affecting the outcome. Human Reproduction (Oxford, England), 12(2), 279-85.Retrieved from http://www.ncbi.nlm.nih.gov/pubmed/9070711

Knight M, Bunch K, Tuffnell D, Jayakody H, Shakespeare J, Kotnis R, Kenyon S, on behalf of MBRRACE-UK (2018). Saving Lives, Improving Mothers' Care - Lessons learned to inform maternity care from the UK and Ireland Confidential Enquiries into Maternal Deaths and Morbidity 2014-16. Oxford: Oxford: National Perinatal Epidemiology Unit, University of Oxford. Retrieved from https://www.npeu.ox.ac.uk/mbrrace-uk/reports

Kuperstein, R., Cahan, T., Yoeli-Ullman, R., Ben Zekry, S., Shinfeld, A., \& Simchen, M. J. (2017). Risk of Aortic Dissection in Pregnant Patients With the Marfan Syndrome. The American Journal of Cardiology, 119(1), 132-137. https://doi.org/10.1016/j.amjcard.2016.09.024

Lin, A. E., Karnis, M. F., Calderwood, L., Crenshaw, M., Bhatt, A., Souter, I., Reindollar, R. H. (2016). Proposal for a national registry to monitor women with Turner syndrome seeking assisted reproductive technology. Fertility and Sterility, 105(6), 1446-8. https://doi.org/10.1016/j.fertnstert.2016.01.042

Lunding, S. A., Aksglaede, L., Anderson, R. A., Main, K. M., Juul, A., Hagen, C. P., \& Pedersen, A. T. (2015). AMH as predictor of premature ovarian insufficiency: A longitudinal study of 120 turner syndrome patients. Journal of Clinical Endocrinology and Metabolism. https://doi.org/10.1210/jc.2015-1621

Lutjen, P., Trounson, A., Leeton, J., Findlay, J., Wood, C., \&Renou, P. (1984). The establishment and maintenance of pregnancy using in vitro fertilization and embryo donation in a patient with primary ovarian failure. Nature, 307(5947), 174-175. https://doi.org/10.1038/307174a0

Männistö, T., Mendola, P., Grewal, J., Xie, Y., Chen, Z., \& Laughon, S. K. (2013). Thyroid diseases 
and adverse pregnancy outcomes in a contemporary US cohort. The Journal of Clinical Endocrinology and Metabolism, 98(7), 2725-33. https://doi.org/10.1210/jc.2012-4233

Matura, L. A., Ho, V. B., Rosing, D. R., \& Bondy, C. A. (2007). Aortic dilatation and dissection in $\begin{array}{llll}\text { Turner } & \text { syndrome. } & \text { Circulation, } & 116(15),\end{array}$ https://doi.org/10.1161/CIRCULATIONAHA.106.685487

Mc Clure, J. H., Cooper, G. M., Clutton-Brock, T. H., \& Centre for Maternal and Child Enquiries. (2011). Saving mothers' lives: reviewing maternal deaths to make motherhood safer: 2006-8: a review. British Journal of Anaesthesia, 107(2), 127-32. https://doi.org/10.1093/bja/aer192

Modi, D. N., Sane, S., \& Bhartiya, D. (2003). Accelerated germ cell apoptosis in sex chromosome aneuploid fetal human gonads. Molecular Human Reproduction, 9(4), 219-25. Retrieved from http://www.ncbi.nlm.nih.gov/pubmed/12651904

Mortensen, K. H., Andersen, N. H., \& Gravholt, C. H. (2012). Cardiovascular Phenotype in Turner Syndrome-Integrating Cardiology, Genetics, and Endocrinology. Endocrine Reviews, 33(5), 677-714. https://doi.org/10.1210/er.2011-1059

Mortensen, K. H., Cleemann, L., Hjerrild, B. E., Nexo, E., Locht, H., Jeppesen, E. M., \& Gravholt, C. H. (2009). Increased prevalence of autoimmunity in Turner syndrome--influence of age. Clinical and Experimental Immunology, 156(2), 205-10. https://doi.org/10.1111/j.13652249.2009.03895.x

Ohl, J. (2008). Oocyte donation in Turner syndrome. Gynecologie, Obstetrique \& Fertilite, 36(9), 886-90. https://doi.org/10.1016/j.gyobfe.2008.06.019

Oktay, K., \& Bedoschi, G. (2014). Oocyte Cryopreservation for Fertility Preservation in Postpubertal Female Children at Risk for Premature Ovarian Failure Due to Accelerated Follicle Loss in Turner Syndrome or Cancer Treatments. Journal of Pediatric and Adolescent Gynecology. https://doi.org/10.1016/j.jpag.2014.01.003

Pasquino, A. M., Passeri, F., Pucarelli, I., Segni, M., \& Municchi, G. (1997). Spontaneous Pubertal 
Development in Turner's Syndrome. The Journal of Clinical Endocrinology \& Metabolism, 82(6), 1810-1813. https://doi.org/10.1210/jcem.82.6.3970

Practice Committee of American Society For Reproductive Medicine. (2012). Increased maternal cardiovascular mortality associated with pregnancy in women with Turner syndrome. Fertility and Sterility, 97(2), 282-4. https://doi.org/10.1016/j.fertnstert.2011.11.049

Schoemaker, M. J., Swerdlow, A. J., Higgins, C. D., Wright, A. F., Jacobs, P. A., \& United Kingdom Clinical Cytogenetics Group. (2008). Mortality in women with turner syndrome in Great Britain: a national cohort study. The Journal of Clinical Endocrinology and Metabolism, 93(12), 473542. https://doi.org/10.1210/jc.2008-1049

Silberbach, M., Roos-Hesselink, J. W., Andersen, N. H., Braverman, A. C., Brown, N., Collins, R. T.; American Heart Association Council on Cardiovascular Disease in the Young; Council on Genomic and Precision Medicine; and Council on Peripheral Vascular Disease. (2018). Cardiovascular Health in Turner Syndrome: A Scientific Statement From the American Heart Association. Circulation. Genomic and Precision Medicine, 11(10), e000048. https://doi.org/10.1161/HCG.0000000000000048

Stochholm, K., Juul, S., Juel, K., Naeraa, R. W., \& Gravholt, C. H. (2006). Prevalence, incidence, diagnostic delay, and mortality in Turner syndrome. The Journal of Clinical Endocrinology and Metabolism, 91(10), 3897-902. https://doi.org/10.1210/jc.2006-0558

Talaulikar, V. S., Conway, G. S., Pimblett, A., \& Davies, M. C. (2018). Outcome of ovarian stimulation for oocyte cryopreservation in women with Turner syndrome. https://doi.org/10.1016/j.fertnstert.2018.11.010

Williams, G. M., Gott, V. L., Brawley, R. K., Schauble, J. F., \& Labs, J. D. (1988). Aortic disease associated with pregnancy. Journal of Vascular Surgery, 8(4), 470-5. Retrieved from http://www.ncbi.nlm.nih.gov/pubmed/3050157

Younis, J. S., \& Laufer, N. (2015). Oocyte Donation Is an Independent Risk Factor for Pregnancy 
Complications: The Implications for Women of Advanced Age. Journal of Women's Health, 24(2), 127-130. https://doi.org/10.1089/jwh.2014.4999 


\begin{tabular}{|c|c|}
\hline & Pre-conceptional visit \\
\hline $\begin{array}{c}\text { Clinical } \\
\text { examination }\end{array}$ & $\begin{array}{c}\text { weight, height, } \\
\text { BMI, BSA } \\
\text { Cardiac murmur } \\
\text { Ambulatory blood pressure }\end{array}$ \\
\hline Thyroid & FT4, TSH, antiTPO antibodies \\
\hline Diabetes & Fasting glycemia $\pm \mathrm{HbAlc}$ \\
\hline Liver & $\begin{array}{l}\text { AST, ALT, GGT, PAL } \\
\quad \pm \text { liver ultrasound }\end{array}$ \\
\hline Kidneys & Plasma creatinin \\
\hline Cardiology & $\begin{array}{c}\text { TTE } \pm \text { CMR including } \\
\text { measurement of ASI } \\
\text { screening for aortic } \\
\text { bicuspid valve/coarctation } \\
\end{array}$ \\
\hline
\end{tabular}




\section{Table I}

\begin{tabular}{|c|c|c|c|c|c|c|c|}
\hline Reference & $\begin{array}{c}\text { Age at } \\
\text { dissection }\end{array}$ & Karyotype & Cardiovascular disease & $\begin{array}{l}\text { Hypertension/ } \\
\text { Pre-eclampsia }\end{array}$ & $\begin{array}{c}\text { Dissection } \\
\text { Timing }\end{array}$ & Pregnancy & Outcome \\
\hline \multicolumn{8}{|l|}{ USA, 1997 (Nagel) } \\
\hline & - & - & no BAV, no coarctation & Yes/No & $1 \mathrm{yr}$ after ART & ART/OD & Deceased \\
\hline & - & - & no BAV, no coarctation & No/No & $3 d$ trimester & - & Deceased \\
\hline \multicolumn{8}{|l|}{ USA, 1998 (Garvey) } \\
\hline & 33 & - & coarctation & Yes/No & 27 weeks, type $A$ & ART/OD & Deceased \\
\hline \multicolumn{8}{|c|}{ Belgium, 2000 (Weytjens) } \\
\hline & 38 & mosaic & no BAV, no coarctation & Yes/Eclampsia & 2 weeks postpartum & - & Alive \\
\hline \multicolumn{8}{|c|}{ USA, 2001 (Beauchesne) } \\
\hline & 30 & - & BAV/operated coarctation & No & 36 weeks, type $A$ & ART/OD & Deceased \\
\hline \multicolumn{8}{|l|}{ Sweden, 2004 (Landin) } \\
\hline & 39 & $45, X / 46, X X / 47, x X X$ & coarctation & Yes/No & $3 \mathrm{~d}$ trimester (7 months) & Natural & Alive \\
\hline \multicolumn{8}{|c|}{ Denmark, 2006 (Gravholt) } \\
\hline & 38 & $45, X$ & no BAV, no coarctation & - & 1 yr post-partum, type B & ART/OD & Deceased \\
\hline \multicolumn{8}{|l|}{ France, 2008 (Ohl) } \\
\hline & 33 & $45, X$ & aortic insufficiency & No & 38 weeks, 1 week post-partum & ART/OD & Deceased \\
\hline \multicolumn{8}{|c|}{ France, 2009 (Boissonnas) } \\
\hline & 33 & $45, X / 46, X X / 46, X Y$ & BAV & No & 37 weeks, type $A, 16$ h post-surgery & ART/OD & Deceased \\
\hline \multicolumn{8}{|l|}{ USA, 2012 (Carlson) } \\
\hline & 27 & mosaic & BAV & No & pregnancy before type $A$ & Natural & Alive \\
\hline & 29 & - & BAV/left subclav anevrysm & No & $3 d$ trimester before type $B$ & ART/OD & Deceased \\
\hline & 48 & - & BAV/Aortic stenosis & - & pregnancy after $2 \mathrm{yr}$ & - & Alive \\
\hline & 48 & mosaic & BAV & Yes/No & pregnancy 17 yr before type $B$ & Natural & Alive \\
\hline \multicolumn{8}{|c|}{ Scandinavia, 2013 (Hagman) } \\
\hline & 36 & $45, X / 46, X Y$ & - & - & 32 weeks & Natural & Alive \\
\hline
\end{tabular}

